\title{
OBSOLÊNCIA PROGRAMADA DE PRODUTOS ELETROELETRÔNICOS: DIMENSÃO SOCIAL, AMBIENTAL ECONÔMICA
}

\section{Prof. Dr. Adilson Rocha - Faculdade de Tecnologia de Sorocaba} adrocha@terra.com.br

Esp. Fernando Rodrigo de Souza - Faculdade de Tecnologia de Sorocaba souzafrn@hotmail.com

\section{Resumo}

O presente trabalho visa discutir os principais impactos sociais, ambientais e econômicos decorrentes da obsolescência programada de produtos eletroeletrônicos, utilizando-a como instrumento para entender a lógica do mercado e as reproduções causadas em seu consumo. Para isso focou-se na avaliação do Núcleo de Gerenciamento Ambiental de Resíduos Eletroeletrônicos de Sorocaba/SP, por meio de revisão bibliográfica e levantamento de dados secundários. Com este projeto espera-se entender a relevância da logística reversa na operacionalização do descarte e reutilização dos resíduos sólidos eletrônicos e analisar a interação entre as áreas envolvidas, ou seja, governo, sociedade e mercado para que os interesses individuais sejam coletivizados e objetivado ao bem comum.

Palavras-Chave: Obsolescência Programada, Logística Reversa, Resíduos Eletroeletrônicos. 


\section{Abstract}

This paper aims to discuss the main social, environmental and economic impacts of the planned obsolescence of electronic products, using it as a tool to understand the logic of the market and reproductions caused by their consumption. This focused on the evaluation of the Center for Environmental Waste Management of Electronics, through literature review and survey of secondary data and with this project is expected to understand the importance of reverse logistics for operating the disposal and reuse of electronic waste and analyze the interaction between the areas involved, so, government, society and market for individual interests are collectivized and objectified the common good.

Keywords: Planned Obsolescence, Reverse Logistics, Electronic Waste.

\section{Introdução}

O referido artigo tem como proposta discutir questões oriundas ao aproveitamento dos resíduos produzidos em contexto geral devido às reproduções terem impactos no âmbito ambiental, social e econômico. Neste aspecto, a partir da legalidade, com a implantação em 2014 do Plano Nacional de Resíduos Sólidos é possível a promoção de ações que visem a reciclagem, reutilização e redução dos resíduos produzidos que, concomitante implicará, positivamente, nas áreas: social, ambiental e econômica.

É perceptível que a produção elevada dos resíduos é influenciada pelo consumo, fazendo com que haja maior rentabilidade ao empresariado, sobretudo; por que são responsáveis pelas alterações e impactos negativos ambientais que influencia a vida cotidiana. Para Fernandez (2004) as transformações ocorridas no meio ambiente são oriundas de causas diversificadas, denominadas naturais e outras não naturais, mas é certo que o desenvolvimento tecnológico atual, concomitante com os hábitos sociais e mercadológicos têm influenciado as mudanças intensificadas no e do ambiente, sobretudo em áreas urbanas.

Os resíduos sólidos (RS) acompanham na mesma proporção ao crescimento populacional, o que implica em maior demanda das coletas destes RS, que devem ser tratados adequadamente para não haver prejuízo ao conjunto de seres vivos, bem 
como ao meio ambiente, assunto amplamente abordado na Conferência da Organização das Nações Unidas (ONU) para o Meio Ambiente e Desenvolvimento, a ECO-92. Nesta estabelecem-se um compromisso da humanidade em relação a manutenção de gerações futuras com desenvolvimento sustentável conciliando justiça social, eficiência econômica e equilíbrio ambiental.

A agenda 21 brasileira segue as sugestões recomendadas pela Conferência da Organização das Nações Unidas (ONU) para o Meio Ambiente e Desenvolvimento e esboça algumas estratégias de enfrentamento do aumento da quantidade de RS descartados, que são:

- Minimização da produção de resíduos;

- Maximização de práticas de reutilização e reciclagem ambientalmente corretas;

- $\quad$ Promoção de sistemas de tratamento e disposição de resíduos compatíveis com a preservação ambiental;

- $\quad$ Extensão de cobertura dos serviços de coleta e destino final (MMA, 1999).

Contudo, é possível verificar a viabilidade deste estudo como instrumento de reflexão sobre a ingestão no meio ambiente de resíduos oriundos de produtos eletroeletrônicos que já foram criados com o objetivo de serem descartados brevemente para favorecer aos interesses econômicos particulares.

Esse artigo tem como objetivo a abstração das questões relacionadas aos principais impactos sociais, ambientais e econômicos decorrentes da obsolescência programada de produtos eletroeletrônicos para entender a lógica do mercado e as reproduções que esta causa no consumo destas mercadorias, a fim de compreender a dicotomia existente entre os interesses dos detentores dos meios de produção, dos trabalhadores e meio ambiente.

Para elaboração desta pesquisa utilizou-se metodologicamente a pesquisa bibliográfica para a fundamentação teórica. Para ser viável o estudo, analisou-se a Lei do estado de São Paulo n 13.576 de 06 de julho de 2009 que "Institui normas e procedimentos para a reciclagem, gerenciamento e destinação final de lixo tecnológico".

Para formulação da pesquisa e após a definição dos objetivos deste estudo construíram-se duas hipóteses: uma que entende que a obsolescência programada é 
um instrumental para os empresários para a obtenção de maior riqueza socialmente produzida; e outra que trata que a logística reversa pode ser considerada como ferramenta para melhor descarte dos resíduos eletroeletrônicos mediante políticas públicas que a favoreçam.

O artigo foi dividido da seguinte forma: seção 1, a Introdução; na seção 2 com a Fundamentação Teórica, visa estabelecer uma relação entre o processo de industrialização e a utilização da logística como ferramenta na operacionalização das atividades vinculadas, todavia na subseção 2.1 Consumo e Tecnologia (comportamento e fetichismo), será possível caracterizar a expressão fetichismo no cotidiano da produção, bem como as ações estabelecidas pela logística no rejeite de produtos tecnológicos, sobretudo com pouca utilização, tendo como referencial a Lei no 13.756 e a interferência para o indivíduo, nas subseções 2.2 Logística Reversa, conceituando e respaldando-se pela legislação, 2.3 Obsolescência Programada de Produtos Eletrônicos, que ressaltou conceito, importância e perspectivas subseção 2.4 Aspectos Sociais, Ambientais e Econômicos que destacou os conceitos e importância, bem como a integração entre esses aspectos; a seção 3. Métodos e Materiais apresenta os mecanismos utilizados para estruturar o trabalho. Os Resultados e Discussões ficaram na seção 4 e, em seguida, na seção 5 as Conclusões e finalizando o artigo com as Referências que nortearam as pesquisas realizadas no artigo.

\section{Fundamentação Teórica}

Sobretudo pós a Revolução Industrial, século XVIII, na Europa, tendo como berço a Inglaterra, é possível constatar diversos e diferentes avanços tecnológicos, associados a abertura econômica do mercado mundial, alicerçada com o sistema econômico baseado no capital. Neste aspecto foram e são criadas ferramentas, como a logística, para redução de custos e sobressair a produção na competitividade mercadológica.

A associação de diversos fatores como as pressões competitivas existentes, os custos (operacionais, de recursos humanos e administrativos), a fidelização de clientes, a obtenção do mercado consumidor que envolvem o mercado para que seja operacionalizada a logística de produtos e serviços, faz com que as organizações, em especial, as com fins lucrativos, planejem e operacionalizem suas atividades 
envolvidas em todo o processo, assim a logística também torna-se viável para melhor atendimento ao consumidor.

Pensando no consumismo impulsionado pelo mercado para que seja possível obter o lucro nas organizações, é pertinente pensar em dois aspectos: o consumo e a logística existente no descarte dos produtos com sua vida pré-estabelecida mesmo antes de seu consumo. Partindo do pressuposto que o mercado capitalista pressiona a indústria para fazer com que produtos tenham vida útil cada vez menor, torna-se necessário compreender a dinâmica de atuação desta teoria.

É sabido que o incentivo ao consumo aliado à vasta oferta de produtos e a acirrada concorrência fez, por exemplo, com que se tornasse mais barata a aquisição de um novo computador em vez do conserto ou upgrade de uma máquina já usada (CALVÃO,et al.,1999). A este fenômeno denominamos obsolescência programada, que foi primeiramente abordado por Bernard London em seu folheto "Ending the Depression Through Planned Obsolescence"(em tradução livre "Acabando com a depressão através da obsolescência planejada"), objetivando acabar com a depressão americana através da obsolescência programada, plano que não foi posto em prática pelas autoridades da época. A teoria proposta por London preconizava que todos os produtos deveriam ter o ciclo de vida interrompido (LONDON, 1932), e com isso impulsionariam as vendas de novos produtos, gerando maior procura e mais empregos, colocando fim à crise.

A obsolescência programada é definida como o encurtamento da vida útil de um bem ou produto, o qual é projetado para que sua durabilidade ou funcionamento se dê apenas por um período reduzido de forma que os consumidores tenham que realizar nova compra em um espaço menor de tempo, aumentando, assim, a lucratividade das empresas (ZANATTA, 2013).

De acordo com Packard (1965), há três maneiras pelas quais um produto pode se tornar obsoleto: obsolescência de função, que ocorre quando um novo produto executa melhor uma determinada função tornando o antecessor ultrapassado; obsolescência de qualidade, que ocorre quando um produto é idealizado e projetado para quebrar ou ser gasto em um tempo menor do que levaria normalmente e, por fim, a obsolescência de desejabilidade, quando um produto que ainda funciona perfeitamente passa a ser considerado antiquado devido ao surgimento de outro estilo ou de alguma alteração que faz com que ele se torne menos desejável. A esta lógica ainda podemos citar a obsolescência instantânea que compreendem os produtos 
descartáveis, como copos plásticos, absorventes, fraldas, entre outros (LEONARD, 2011).

\section{Consumo e Tecnologia (Comportamento e Fetichismo)}

Esta pesquisa parte da conceituação do fetichismo do mercado. Para tanto respalda-se em lamamoto (2007),

O fetichismo dos mercados apresenta as finanças como potências autônomas ante às sociedades nacionais e esconde o funcionamento e a dominação operada pelo capital transnacional e investidores financeiros que contam com o efetivo respaldo dos Estados nacionais e das grandes potencias internacionais. (IAMAMOTO, 2007, p. 120).

O principal interesse que envolve o fetichismo dos mercados é a concentração da riqueza socialmente produzida, o que deixa os países com economia periférica dependente de grandes potencias mundiais, o que promove a exploração dos recursos naturais e humanos destas nações com pouco poder de investimento em tecnologia, assim tais empresas se instalam nestes locais, principalmente para ter uma produção com menor custo e o objetivo da capitalismo, ou seja, o lucro retorna para tais países, em especial, na forma de juros.

Para tanto, ao indivíduo, é proporcionado o consumismo baseado nos interesses do empresariado: lucro e juros. Provocando a falsa necessidade da utilização de produtos, sobretudo tecnológicos e seu constante descarte, Rogers (2009) relata que nós inutilizamos por ano cerca de 2 bilhões de telefones celulares, 50 milhões de monitores de computador, porém há 2 bilhões de diferentes aparelhos eletrônicos que chegarão às latas de lixo, ou seja, local destinado aos produtos que não são utilizados ao consumo, podem ser objetos que não possuem mais valor ou utilidade, instrumentos sem valor econômico, sobras de produtos domésticos e ou industriais (AISEE, et al 1982), mas neste caso estes materiais poderiam ser reaproveitados.

Este movimento estabelece o resíduo eletrônico como sendo um setor com crescimento representativo e elevado comparado as diversas categorias de resíduo 
classificados pelas NBRs (Normas Brasileiras Reguladoras). Com tal realidade abordase a logística reversa.

Pensando neste descarte consciente e o possível contraponto entre a economia e a sustentabilidade econômica, a Europa, parte dos Estados Unidos, Japão e o estado de São Paulo instituem políticas públicas para a operacionalização do descarte dos resíduos tecnológicos, porém é possível considerar algumas fragilidades como atribuição do custo da logística reversa ao produtor, responsabilizando-o por todo o ciclo de vida do produto, porém não considera:

- Os materiais produzidos por organizações fechadas/falidas, assim de quem é a responsabilidade?

- Produtos fabricados a partir de peças de diversas outras empresas, como é comum entre os materiais tecnológicos. A logística reversa se aplica a empresa que disponibiliza o produto final ao consumo?

- Aparelhos oriundos do mercado informal, ou seja, os Xinglings (expressão popular utilizada para denominar os originados da China (made in China)) a obrigatoriedade da efetivação da política seria pelo Estado, seja através da fiscalização para não haver tal comércio tão significativo ou na logística reversa?

A legislação atual não preenche estas lacunas existentes na realidade e não podem ser desconsideras e responsabilizar apenas os produtores pelo destino dos resíduos eletrônicos, o que não significa que não seja um bom passo para uma logística reversa, porém o meio ambiente continuaria sendo contaminado por tais descartes.

\section{Logística Reversa}

A logística reversa tem como premissa o retorno de produtos, redução na fonte, reciclagem, substituição de materiais, reuso de materiais, disposição de resíduos, reforma, reparação e remanufatura (STOCK, 1998).

Ao tratar da logística reversa de equipamentos eletroeletrônicos é preciso considerar todas as questões que envolvem o descarte dos resíduos, ou seja, é preciso haver uma gestão e planejamento, trazendo a definição das responsabilidades e alternativas para a condução da política destinada à logística reversa.

Em 06 de julho de 2009, no estado de São Paulo, houve a instituição da Lei no 13.576 que "Institui normas e procedimentos para a reciclagem, gerenciamento e 
destinação final de lixo tecnológico", contendo 12 artigos, dos quais 04 foram vetados. No artigo 1ำ dá-se a responsabilidade para a destinação dos lixos tecnológicos de forma que não prejudique tanto o meio ambiente quanto a sociedade, porém em seu parágrafo único estabelece uma responsabilidade solidária entre as organizações que "produzam, comercializem ou importem produtos e componentes eletroeletrônicos" (SÃO PAULO, Lei no $13.576,2009$ ), como é possível perceber não há uma obrigatoriedade na condução desta prática, assim pode causar a transferência de responsabilidade entre os envolvidos caso não haja a absorção da responsabilidade das empresas.

Segundo esta mesma Lei, artigo $2^{\circ}$, traz a definição de lixo tecnológico como sendo:

Artigo $2^{\circ}$ - Para os efeitos desta lei, consideram-se lixo tecnológico os aparelhos eletrodomésticos e os equipamentos e componentes eletroeletrônicos de uso doméstico, industrial, comercial ou no setor de serviços que estejam em desuso e sujeitos à disposição final, tais como:

I - componentes e periféricos de computadores;

II - monitores e televisores;

III - acumuladores de energia (baterias e pilhas);

IV - produtos magnetizados. (SÃO PAULO, Lei no⒔576, 2009).

Ou seja, são aparelhos e equipamentos que não tenham possibilidades de uso, após a tentativa e investigação para a possível reutilização de partes destes materiais, proporcionando dirimir o descarte conforme é estabelecido no artigo $3^{\text {o }}$

Artigo $3^{\circ}$ - A destinação final do lixo tecnológico, ambientalmente adequada, dar-se-á mediante:

I - processos de reciclagem e aproveitamento do produto ou componentes para a finalidade original ou diversa;

II - práticas de reutilização total ou parcial de produtos e componentes tecnológicos;

III - neutralização e disposição final apropriada dos componentes tecnológicos equiparados a lixo químico. (SÃO PAULO, Lei no 13.576, 2009). 
Caso não seja possível a reutilização de parte dos equipamentos ou aparelhos eletrônicos, sendo em última instância seu descarte, deve seguir outras legislações como a ambiental, normas de saúde e de segurança pública, bem como os impedimentos existentes em cada órgão público responsável conforme é estabelecido no parágrafo $1^{\circ}$ do artigo $3^{\circ}$ desta lei estadual; porém em seu parágrafo seguinte é instituído um outro grupo de lixo tecnológico, os que possuem substância tóxicas, devendo os responsáveis obter licença especifica para o descarte, tornando o descarte burocrático e demorado, já que não indica termo para a liberação de tal licença, deixando subentendido que a empresa deve estocar tais lixos enquanto não há tal liberação.

O artigo $4^{\circ}$ desta Lei estadual estabelece a responsabilidade das empresas na viabilização de informação aos consumidores, a qual as embalagens ou rótulos devem garantir de forma destacada instruções sobre o descarte do lixo tecnológico com é possível verificar:

Artigo $4^{\circ}$ - Os produtos e componentes eletroeletrônicos comercializados no Estado devem indicar com destaque, na embalagem ou rótulo, as seguintes informações ao consumidor:

I - advertência de que não sejam descartados em lixo comum;

II - orientação sobre postos de entrega do lixo tecnológico;

III - endereço e telefone de contato dos responsáveis pelo descarte do material em desuso e sujeito à disposição final;

IV - alerta sobre a existência de metais pesados ou substâncias tóxicas entre os componentes do produto. (SÃO PAULO, Lei no 13.576, 2009).

No artigo 5ำ desta legislação tem-se a mesma problemática que foi apresentada no artigo $1^{\circ}$, sobretudo em seu parágrafo único, ou seja, não é estabelecido um direcionamento de quem será a responsabilidade direta em disponibilizar pontos para o descarte do lixo tecnológico ao consumidor.

Trataremos do artigo $8^{\circ}$ da Lei $n^{\circ} 13.576$, pois os demais foram vetados. Neste texto coloca que todas os valores arrecadados com as taxas e multas oriundas desta Lei serão destinados "[...] I - programas de coleta seletiva; II - ações de destinação 
final ambientalmente adequada" (SÃO PAULO, Lei $\left.n^{\circ} 13.576,2009\right)$. Os artigos $9^{\circ} \mathrm{e}$ $10^{\circ}$ foram vetados, no $11^{\circ}$ coloca "As despesas decorrentes da execução desta lei correrão à conta de dotações orçamentárias próprias da Secretaria do Meio Ambiente, suplementadas se necessário" (SÃO PAULO, Lei n $13.576,2009$ ) e o $12^{\circ}$ expõem a data que tal Lei entra em vigor.

Concomitante a esta Lei do estado de São Paulo, tem-se a Política Nacional de Resíduos (PNR) no 12.305 de 02 de agosto de 2010 que alterou a Lei no 9.605, de 12 de fevereiro de 1998, a PNR

[...] trata em seu Artigo 6, VIII do resíduo sólido reutilizado como um todo, e no Artigo 33, VI dos produtos eletroeletrônicos e seus componentes. Mas a principal diferença entre a Lei 12.305, para com a Lei 13.576 do estado de São Paulo, é que essa última, trata exclusivamente do lixo tecnológico (CAMPOS; OLIVEIRA, 2012).

A evolução das políticas municipais de coleta seletiva em Sorocaba se iniciou em 1995 com a Lei n 4.942/95, que obrigou a Prefeitura Municipal a implantar e manter recipientes para a coleta de materiais recicláveis no município. Posteriormente, a Lei no 5006/95 regulamentou sobre a coleta seletiva dos resíduos comerciais e residenciais e, por fim, a Lei $n^{\circ} 5.192 / 96$, revogou as leis anteriores e instituiu a coleta seletiva no âmbito do município.

A princípio foi iniciada a coleta seletiva informal, apoiada na existência da Cooperativa de Reciclagem de Sorocaba - CORESO, que foi incubada pelo Centro de Estudos e Apoio ao Desenvolvimento Emprego e Cidadania - CEADEC. O modelo adotado pela CORESO consistia na coleta seletiva dos materiais recicláveis "porta-aporta", com os catadores interagindo na comunidade e realizando a coleta dos materiais recicláveis com um caminhão. Outras iniciativas foram iniciadas por outras entidades, porém de maneira isolada e sem o pleno apoio de um programa municipal de coleta seletiva em parceria com organizações de catadores. 


\section{Obsolescência Programada de Produtos Eletrônicos}

Em 2014, o Idec (Instituto Brasileiro de Defesa do Consumidor) e a Market Analysis - instituto especializado em pesquisas de opinião - divulgaram pesquisa inédita sobre as percepções e os hábitos dos consumidores brasileiros, com relação ao uso e descarte de aparelhos eletrônicos: eletrodomésticos (forno de micro-ondas, fogão, geladeira ou freezer e lavadora de roupas), eletrônicos (televisão, DVD e bluray), aparelhos digitais (câmera fotográfica, computador e impressora) e celulares, apontou que de todos eles, o celular é o aparelho que tem menor duração e possui um ciclo de vida de, em média, menos de 3 anos e dificilmente ultrapassa cinco anos.

De acordo com a Política Nacional de Resíduos Sólidos - PNRS, os fabricantes de algumas categorias de produtos, entre eles os de aparelhos eletroeletrônicos, devem ser responsáveis pelo recolhimento, pela reciclagem e pela destinação adequada de seus produtos, o que caracteriza o processo de logística reversa.

\section{Aspectos Sociais, Ambientais e Econômicos}

Toda ação remete a uma reação e com o reaproveitamento de resíduos eletroeletrônicos não seria diferente, visto que estas ações impactam diretamente e principalmente em três setores: econômico, social e ambiental.

Não é possível pensar em crescimento econômico e não atrelá-lo ao setor social e ambiental, ações que proporcionem a sustentabilidade, menores reflexos ambientais e maior beneficio social, como a diminuição de enchentes, problemas climáticos, qualidade de vida, entre outros.

Com o barateamento dos ciclos industriais através das ações de reaproveitamento de resíduos eletroeletrônicos é possível elevar o lucro dos capitalistas, além de diminuir os impactos ambientais.

Já na perspectiva dos catadores de resíduos eletroeletrônicos os ganhos não são suficientes para o acúmulo da riqueza, estando mais propenso ao suprimento das suas necessidades básicas como: alimentar, habitacional e outras que forem priorizadas por estas pessoas.

Os impactos sociais que processo de reciclagem traz diz respeito ao cotidiano dos envolvidos, tanto diretamente como indiretamente, de forma mais ou menos intensa. Traz em seu bojo consequências positivas para a sociedade em geral, como a 
diminuição do volume do lixo. $\mathrm{O}$ ato de reciclar pode ser visto como uma ação educativa, proporcionando a polidez ao indivíduo, gerando benefícios sociais para si e aos que convivem com estas pessoas, afastando atitudes que prejudiquem algo ou alguém, pois é reaproveitado produtos que afetariam o meio ambiente - contaminação de águas, solo, dispensação incorreta do lixo - por exemplo.

Outro fator social a ser identificado é a geração de emprego formal e mesmo o informal, assim faz com que contribua para o desenvolvimento da sua cidadania, uma vez que lhe é garantido ganho econômico para que posteriormente tenha autonomia em utilizar da melhor maneira que achar, ou seja, proporciona o resgate de sua individualidade e poder de decisão, distanciando-os de políticas paternalistas que não fazem esta recuperação da identidade humana, apenas há a "doação".

Nos dias atuais (século XXI) o meio ambiente não é visto como parte isolada das questões sociais e econômicas, já que faz parte do processo de "evolução" do cotidiano humano. Todas as ações que visem reaproveitar produtos, melhorar o descarte e diminuir o volume do lixo trás consequências positivas ao meio ambiente e obviamente ao homem.

Podemos frisar como benefícios ambientais: a diminuição do volume de lixo, ocasionando o aumento da vida útil dos aterros sanitários; diminuição dos "lixos" nas vias públicas, rios, lagos e etc.; prolongamento das fontes naturais; diminuição das contaminações das terras e lençóis freáticos; entre outros.

\section{Métodos e materiais}

A metodologia utilizada para a obtenção de informações pertinentes ao atendimento dos objetivos do presente trabalho focou na avaliação do Núcleo de Gerenciamento Ambiental de Resíduos Eletroeletrônicos, proposto pelo município de Sorocaba, através de revisão bibliográfica e levantamento de dados secundários. 


\section{Resultados e discussões}

O estudo teve como objeto de pesquisa empírica o Núcleo de Gerenciamento Ambiental de Resíduos Eletroeletrônicos de Sorocaba, todavia não foi possível a apresentação das respostas referentes ao questionário encaminhado ao coordenador, pois não houve a devolutiva do documento, mesmo após diversas solicitações, desta forma o pesquisador deve estar preparado para que haja a adaptabilidade no percurso metodológico do estudo, neste aspecto utilizou-se de informações contidas em fontes secundárias, obtidas sobretudo com reportagens disponíveis na internet, visto que este núcleo não possui site oficial.

De acordo com o Jornal Ipanema (05/07/2015), o Núcleo teve sua inauguração em 09 de dezembro de 2010, tendo como principal objetivo "dar um destino correto ao chamado 'lixo eletrônico', pois como é possível observar com a análise deste estudo, que o descarte incorreto traz prejuízos ao meio ambiente, social e econômico. $\mathrm{Na}$ mesma reportagem fazem menção à ampliação dos produtos que são entendidos como eletrônicos, para que a sociedade não associe apenas a computadores, neste sentido o referido local entende como "lixo eletrônico":

Televisões, monitores e CPUs de computadores, ventiladores, ferros de passar roupa, aparelhos de ar-condicionado, aspiradores, relógios, balanças, calculadoras, telefones, máquina de costura, radiografias, pilhas e baterias que não funcionam mais. Esses são alguns exemplos de materiais que podem ser encaminhados ao Núcleo de Resíduos Eletroeletrônicos de Sorocaba $[\ldots]$.

Como grande parte dos produtos eletroeletrônicos tem sua vida útil pré-definida mesmo antes de seu consumo para que, sobretudo, haja um maior mercado consumidor, denominado tecnicamente como obsolescência programada tenha um descarte correto, assim é possível preservar questões ambientais, gerar empregos e assim proporcionar renda a diversos núcleos familiares que, inevitavelmente, estão na condição de vulnerabilizados, porém também produz a concentração da riqueza aos grandes empresários do seguimento. 
O Núcleo foi criado por meio de ações da prefeitura de Sorocaba, representada pela Secretaria de Parcerias e a cooperativa de reciclagem Reviver conforme é possível verificar na mesma reportagem

A cooperativa beneficiada pelo Núcleo de Gerenciamento de Resíduos Eletroeletrônicos é a Reviver - parceira da Prefeitura no Programa Municipal de Coleta Seletiva. Todos os materiais e resíduos extraídos dos produtos eletroeletrônicos do Núcleo são separados e vendidos para empresas que trabalham com cada tipo de produto. Uma parte desse valor de venda é utilizada para a destinação dos resíduos tóxicos extraídos dos eletroeletrônicos.

Porém, uma das dificuldades da operacionalização do trabalho é o envio dos produtos pelos munícipes, visto que não há uma regularidade no recolhimento por parte do Núcleo dos resíduos eletrônicos, assim responsabiliza o cidadão no que tange o envio dos produtos ao núcleo:

As Casas do Cidadão e os terminais de ônibus da cidade são postos de coleta de pilhas e baterias. Para dar a destinação correta ao produto, o munícipe pode levá-los até o Núcleo Ambiental de Resíduos Eletroeletrônicos ou verificar se o caminhão da coleta seletiva passará pelo seu bairro.

As ações deste gênero devem privilegiar concomitante ao objetivo central o planejamento do gerenciamento logístico quanto ao recebimento dos produtos, levando em consideração as dificuldades dos indivíduos no manuseio e entrega dos produtos em local com acesso não facilitado como é o caso do Núcleo.

Conforme o "R-3 - Plano Municipal de Gestão Integrada de Resíduos Sólidos de Sorocaba - SP - Versão Preliminar" de julho/2014 é possível quantificar o trabalho desenvolvido pelo Núcleo:

Desde a inauguração do Núcleo em dezembro de 2010, a Prefeitura Municipal (2013) estima já terem sido recebidas 700 toneladas de resíduos eletrônicos, também chamados de "e-lixo", além de 12 toneladas de pilhas e baterias, que também são 
coletadas no Núcleo. Em média, recebem-se 30 toneladas de resíduos eletroeletrônicos mensalmente, com destaque para computadores e televisores. A SERP informou em 2012 que havia o recebimento de 100 a 150 televisores por semana.

Devido ao crescimento do trabalho executado pelo Núcleo desde sua inauguração que dispunha de um galpão de $300 \mathrm{~m}^{2}$ em dezembro de 2011, o setor foi remanejado para um local de $1000 \mathrm{~m}^{2}$, ou seja, mais que o triplo da área anterior, conforme o "R-3 - Plano Municipal de Gestão Integrada de Resíduos Sólidos de Sorocaba - SP - Versão Preliminar" de julho/2014.

Conforme mencionado o trabalho do Núcleo é operacionalizado com a intervenção da cooperativa Reviver, conforme o Plano municipal

O trabalho desenvolvido pela Reviver pode ser considerado como manufatura reversa, uma vez que grande parte dos componentes retirados dos eletroeletrônicos são utilizados no processo produtivo de outros produtos.

Para a correta avaliação do resíduo recebido, triagem técnica, manuseio de ferramentas, desmontagem e comercialização do material, os cooperados da Reviver foram capacitados por uma empresa privada parceira da prefeitura, a Interamerican Gerenciamento Ambiental.

Ou seja, pretende-se qualificar e tornar o mais técnico possível as ações realizadas no Núcleo de Sorocaba para que os resultados sejam satisfatório em aspectos múltiplos e já destacados: social, ambiental e econômico. 


\section{Conclusões}

Com o estudo foi possível observar que a logística reversa auxilia no descarte correto de resíduos sólidos, bem como é um instrumental que conduz a reciclagem, reutilização e redução destes produtos, proporcionando o melhoramento de seu volume. Todavia a hipótese que entende que a obsolescência programada é um instrumental para os empresários para a obtenção de maior riqueza socialmente produzida foi possível ser confirmada, já que os valores dos produtos pagos são superiores, ocasionando em maior retorno financeiro para o empresário, motivo que movimenta o interesse dos detentores do meio de produção ingressar em um negócio.

A outra hipótese traçada neste estudo que a logística reversa pode ser considerada como ferramenta para melhor descarte dos resíduos eletroeletrônicos mediante políticas públicas que a favoreçam também é confirmada, pois é considerado que o instrumental informado não terá relevância em sua prática se não houver o envolvimento do Estado com ações que viabilize sua utilização.

Neste aspecto, deve-se considerar que o descarte correto dos resíduos sólidos, seja para sua reciclagem, reutilização e redução favorece principalmente o tripé: social, ambiental e econômico. Desta maneira, é preciso maior interação entre as áreas envolvidas, ou seja, governo, sociedade e mercado para que os interesses individuais sejam coletivizados e objetivado ao bem comum, visto que as questões ambientais implicam(rão) no cotidiano de todo ecossistema de forma negativa. 


\section{Referências Bibliográficas}

AISSE, M. M.; OBLADEN, N. L.; SANTOS, A. S. Aproveitamento dos Resíduos Sólidos Urbanos. Curitiba: CNPq/ ITAH/ IPPUC/ LHISAMA- UCPr. [1982]. 107p.

CALVÃO, A. M.; et al. O Lixo Computacional na Sociedade Contemporânea. Cascavel: I ENINED - Encontro Nacional de Informática e Educação, 1999. Disponível em $<$ http://www.inf.unioeste.br/enined/2009/anais/enined/A29.pdf>. Acesso em 10 de julho de 2014.

CAMPOS, L. F. L.; OLIVEIRA, M. Gestão do Resíduo Tecnológico Gerado pela Tecnologia da Informação. Revista Eletrônica Machado Sobrinho, 2012. Disponível < em:

http://www.machadosobrinho.com.br/revista_online/publicacao/artigos/Artigo02REMS4. pdf. Acesso em 10 ago. 2014.

FERNANDEZ, F. A. dos S. O poema imperfeito: crônicas de Biologia, conservação da natureza, e seus heróis. 2. ed. Curitiba: UFPR, 2004.

IAMAMOTO, M. V. Serviço Social em tempo de capital fetiche: capital financeiro, trabalho e questão social. São Paulo: Cortez, 2007.

IDEC-Instituto Brasileiro de Defesa do Consumidor. Mais da metade dos equipamentos eletrônicos é substituída devido à obsolescência programada. 2014. Disponível em < http://www.idec.org.br/o-idec/sala-de-imprensa/release/mais-da-metade-dosequipamentos-eletronicos-e-substituida-devido-a-obsolescencia-programada>. Acesso em 05 de maio de 2015.

JORNAL

Ipanema.

2015.

Disponível

em: http://jornalipanema.com.br/noticias/sorocaba/25326-lixo-eletronico-tem-destinacaocorreta-em-sorocaba. Acesso em 15 de maio de 2015.

LEONARD, Annie. A história das coisas: da natureza ao lixo, o que acontece com tudo que consumimos. Rio de Janeiro: Zahar, 2011. 302 p. 
LONDON, B. Ending the Depression Through Planned Obsolescence. 1932

MMA (Ministério do Meio Ambiente), 1999. Agenda 21 Brasileira: Bases para a Discussão. Brasília: MMA.

PACKARD, V. A estratégia do desperdício. São Paulo: Ibrasa, 1965. 311 p.

R-3 - Plano Municipal de Gestão Integrada de Resíduos Sólidos de Sorocaba - SP Versão Prelimina. 2014.

http://www.meioambientesorocaba.com.br/sema/UserFiles/file/Residuos\%202014/Relat \%C3\%B3rio\%20R-3\%20PMGIRS.pdf. Acesso em 15 de maio de 2015.

ROGERS, Elisabeth; Kostigen, Thomas M. O Livro verde. Tradução: Bernardo Araújo. 1 ed. Rio de Janeiro: Sextante, 2009.

STOCK, J. R., Development and Implementation of Reverse Logistics Programs, Oak Brook, IL: Council of Logistics Management; 1998.

ZANATTA, M. A Obsolescência Programada Sob a Ótica Do Direito Ambiental Brasileiro. 2013. <http://www3.pucrs.br/pucrs/files/uni/poa/direito/graduacao/tcc/tcc2/trabalhos2013_2/m arina_zanatta.pdf >. Acesso em 17 de agosto de 2014. 